\title{
Re: Imaging the urologic patient: the utility of intravenous pyelogram in the CT scan era
}

\author{
Mustafa Resorlu • Gurhan Adam • Fatma Uysal • \\ Eyup Burak Sancak $\cdot$ Huseyin Ozdemir
}

Received: 28 July 2013/Accepted: 17 August 2013/Published online: 25 August 2013

(C) Springer-Verlag Berlin Heidelberg 2013

\section{Dear Editor,}

We read with great interest the recent article by Hale et al. [1] on the comparative study of intravenous urography (IVU) and computerized tomography (CT). They concluded that IVU has a limited clinical role on the evaluation of the urologic patient, and thus, its use should be strictly limited to highly select cases. We congratulate the authors for their work and thank them for bringing this important topic to our attention; however, we feel that some issues described in their paper need further discussion.

We know that noncontrast $\mathrm{CT}$ is the most accurate imaging method for identifying urinary stones, and it has become the standard test for diagnosis of acute flank pain [2]. It offers the advantages over IVU of avoiding contrast allergy or nephrotoxicity and has ability to determine the other causes for abdominal pain. However, most of the patients with a history of flank pain return with similar symptoms and need to undergo repetitive CT examinations. Furthermore, current EAU guidelines recommend a contrast study (enhanced CT or IVU) if stone removal is planned, because the anatomy of the renal collecting system needs to be assessed prior to stone surgery or shock wave lithotripsy [2]. But use of repeated CT or IVU would increase the risk of cancer development. Epidemiological trials have reported an association between doses of radiation administered in CT and an increased risk of malignancy [3]. Recently, published studies also reported a theoretic increased risk of fatal cancer in pediatric and

M. Resorlu ( $₫) \cdot$ G. Adam · F. Uysal ·

E. B. Sancak · H. Ozdemir

School of Medicine, Canakkale Onsekiz Mart University,

Canakkale, Turkey

e-mail: mustafaresorlu77@gmail.com adult population as a result of single CT scan, based on data from similar levels of exposure to radiation during the atomic bombings of Nagasaki and Hiroshima [4, 5]. It was underlined that a single abdomen CT in infants would cause in one CT-related death per 550 scans [6]. Therefore, we believe that combination of ultrasonography and abdominal radiography may be considered in the evaluation of acute flank pain especially in children and patients with known urinary stone disease. Noncontrast CT may be reserved for those patients with suspected urolithiasis but negative findings on plain radiography and ultrasonography.

\section{References}

1. Hale Z, Hanna E, Miyake M et al (2013) Imaging the urologic patient: the utility of intravenous pyelogram in the CT scan era. World J Urol [Epub ahead of print]. doi:10.1007/s00345-013-1085-4

2. Türk C, Knoll T, Petrik A et al (2013) Guidelines on urolithiasis p46. Available at: http://www.uroweb.org/gls/pdf/20_Urolithiasis.pdf

3. Resorlu B, Kara C, Resorlu EB et al (2011) Effectiveness of ultrasonography in the postoperative follow-up of pediatric patients undergoing ureteroscopic stone manipulation. Pediatr Surg Int 27:1337-1341

4. Brenner D, Elliston C, Hall E et al (2001) Estimated risks of radiation-induced fatal cancer from pediatric CT. AJR 176:289-296

5. Catalano O, Nunziata A, Altei F et al (2002) Suspected ureteral colic: primary helical $\mathrm{CT}$ after unenhanced radiography and sonography. AJR 178:379-387

6. Tepeler A, Akman T, Binbay M et al (2012) Letter to the editor regarding the article "effectiveness of ultrasonography in the postoperative follow-up of pediatric patients undergoing ureteroscopic stone manipulation”. Pediatr Surg Int 28:215 